\title{
Development of a Village Based Treatment Model for Afghanistan
}

Tay Bian How ${ }^{1}$, Morales Brian², V. Thirumagal ${ }^{3}$,Muhammad Ayub ${ }^{4}$.

${ }^{1}$ Asian Centre for Certification and Education of Addiction Professionals (ACCE), The Colombo Plan; ' Global Drug Demand Reduction Programme, Bureau for International Narcotics and Law Enforcement Affairs (INL), United States Department of State; ${ }^{3}$ T.T. Ranganathan Clinical Research Foundation (TTK Hospital), Chennai, India; ${ }^{4}$ Drug Advisory Programme (DAP), The Colombo Plan.

Correspondence: email: bian.howtay@colomboplan.org

\section{Abstract}

Addiction treatment has posed several challenges for cities in developing countries all over the world. Limited addiction treatment facilities, lack of trained personnel, dearth of evidence-based practices and social stigma often function as barriers to treatment. Moreover, the quality of treatment has also been a cause for concern as many countries have been reporting high relapse rates. These limitations are magnified further in rural communities where drug use is rising and access to treatment for substance use disorders is scarce. Additionally, practical barriers (e.g. distance from treatment centre, transportation) are often too great to overcome, necessitating a specialised approach where treatment travels from urban to rural setting.

Afghanistan is the world's largest producer of opium and heroin. Afghans particularly living in rural settings have no access to healthcare services, including treatment for drug dependence. The widespread dependency on opium poses serious debilitating social, economic and health consequences, not just for those who are addicted, but also for their families and communities. In a meeting between the Colombo Plan Drug Advisory Programme's officials and the tribal leaders of Balkh Province, the tribal leaders shared that more than $50 \%$ of their villagers (including women and children) are addicted to drugs. In 2011, a drug use prevalence survey was commissioned by the Bureau for International Narcotics and Law Enforcement Affairs, U.S. Department of State, for two rural villages of Balkh province based on toxicology. The study concluded that $33.5 \%$ of villagers in Ana Gilday (total pop. 705 ) and 36.1\% of villagers in Kohna Kaldar (total pop. 753) tested positive for opiates. For comparison, the prevalence rate of drug use among the urban population of Mazar-e-Sharif, the provincial capital of Balkh province is substantially lower.

In view of the above-mentioned situation, the Colombo Plan Drug Advisory 
Programme initiated a Village Based Treatment Programme in four villages in Balkh province in Afghanistan. This paper will deliberate the genesis and adaptation of the South Indian widely-implemented Camp Approach to treat drug addicts, to pilot a village-based treatment in Afghanistan. The paper will also elaborate on the rationale, framework and initial treatment outcome of the village-based intervention.

Keywords: Village Based Treatment Programme, Balkh province

\section{Introduction}

Addiction treatment has posed several challenges for cities in developing countries all over the world. Limited addiction treatment facilities, lack of trained personnel, dearth of evidence-based practices and social stigma often function as barriers to treatment. ${ }^{1}$ Moreover, the quality of treatment has also been a cause for concern as many countries have been reporting high relapse rates. These limitations are magnified further in rural communities where drug use is rising and access to treatment for substance use disorders is insufficient. Additionally, practical barriers (e.g. distance from treatment centre, transportation) present barriers that are often too great to overcome, necessitating a specialised approach where treatment travels from urban to rural setting.

Afghanistan is the world's largest producer of opium and heroin. The alarming prevalence of drug use among adult men and women, adolescents, and children is facilitated through the cheap availability of opium and heroin in a country that produces $74 \%$ of the world's opiates. ${ }^{2}$ The drug use prevalence among urban populations based on the 2012 Afghanistan National Urban Drug Use Survey, which included household and toxicology surveys, was 5.3\% of Afghans living in urban areas or $11.4 \%$ of urban households. Two targeted village drug use surveys in the Kaldar district of northern Balkh province identified opiate use prevalence at; $33.5 \%$ in Ana Gilday village and 36.1\% in Kohnar Kaldar village. Furthermore, use among women and children in both villages was alarming, with $35.8 \%$ and $40.3 \%$ of adult females and $33.3 \%$ and $37.2 \%$ of children testing positive in both villages, respectively. ${ }^{3}$

In response, the Bureau for International Narcotics and Law Enforcement Affairs (INL) of the U.S. Department of State commissioned a National Rural Drug Use Survey that will provide a national rural drug use rate. This survey, in combination with the urban survey, will provide a more accurate national prevalence rate, since rural populations, comprising $76 \%$ of Afghanistan's population trend toward higher drug use than their urban counterparts.

Numerous factors lead rural populations to use drugs, particularly opium and hashish. Traditional usage as medication, lack of public awareness on the harms 
of opium, and frequent contact with opiates (e.g. during cultivation and trafficking) are some of the factors that contribute to high addiction rates in rural communities. ${ }^{4}$ In addition, access to healthcare services is limited in most of the country and many have turned to opium as a cure for their medical problems. A widespread dependency on opium use has been established which has serious social, economic and health effects, not just for those who are addicted, but also for their families and communities.

Use of opium among females is increasing in Afghanistan creating new social problems such as the disintegration of the family unit, addiction in children and neglect of children's basic needs like food, sanitation and education. Addiction among women is more problematic to community social structures than addiction among males because of the unique nature of women's responsibilities in childcare and to the family unit.

In provinces of northern Afghanistan like Balkh, Jawzjan, Kunduz, Takhar and Badakhshan, opium is often traded like tea and is largely considered to be a medicine rather than a dangerous drug. Significant proportions of people who are dependent on opium in these provinces are women who use it to dull the pain caused by working for many hours on heavy weaving looms. However, the dependency is affecting their health, livelihoods and ability to care for their children.

\section{Rationale for Community Based Treatment}

Financial constraints present another deterrent to effective treatment services in resource-restricted rural communities. While ensuring that the quality of treatment services is essential, these services also need to be offered at a low cost as the communities are predominantly from a lower income group. Community-based outreach treatment camps have been presented as a viable approach. Utilising a core team of well-trained and skilled clinical staff makes treatment in various locations within the community possible. This approach combines effective services with low cost delivery systems making it a win-win situation for all the stakeholders. The treatment providers are able to reach out to people in need, the funders are able to help more people with fewer resources and addicted persons are able to access specialised addiction treatment services in their own communities.

Addressing addiction through a community approach has been gaining momentum since the late 1980s. A perceptible shift in public health approaches has made community-based services available in non-specialist settings. Primary health care settings are slowly emerging as locations to identify individuals with substance use problems, provide brief intervention for those with mild or moderate problems, and function as referral sources to deliver specialised services. Apart from early 
identification and brief intervention, community based addiction treatment services have also been found to be effective. Few documented community based treatment approaches exist.

Evans describes community based addiction treatment services and $75 \%$ abstinence following community mobile treatment in Anahim Lake Reserve in Canada. ${ }^{5}$ Poshyachinda describes detoxification programmes carried out by Buddhist monks in Tam Kraborg Temple in Thailand. ${ }^{6}$

In 1987, T. T. Ranganathan Clinical Research Foundation popularly known as TTK Hospital initiated its outreach community base camps in rural areas of Tamil Nadu, India. While conducting awareness and life skill programmes in a village school, the representatives were persuaded by the village leaders to offer addiction treatment facilities in the village setting. TTK which had already established itself as a professionally managed residential addiction treatment centre in the city of Chennai had the requisite expertise. But to offer these services in a village based setting posed a challenge. What started off as a onetime effort in 1987 became a regular part of the centre's treatment initiatives. Since then, TTK conducts six camps in a year in different rural settings to treat alcohol dependence for the rural poor for whom addiction treatment would otherwise be inaccessible. Each camp takes in about 25 patients and treatment is provided free of cost. Ranganathan, one of the key architects of the camp approach, in her doctoral study reported a recovery rate of $66.9 \%$ at the end of one year. ${ }^{7}$

\section{Transformation from Camp Approach to Village Based Treatment}

TTK Hospital conducts the community based treatment camp conducted in three phases.

Phase 1: This phase helps build community support and identifies clients who will participate in the treatment camp. This phase prepares the ground for the short- term intensive, highly structured abstinence based treatment approach. The key activities in this phase include:

- Identification of the community wherein treatment is to be provided

- Training a core group of community representatives to support the treatment initiative

- Sensitising the community to addiction related problems, creating awareness to recognise addiction as a disease and the need for treatment

- Inviting persons with alcohol problems to access treatment along with their family members 
- Screening and building motivation amongst those identified with alcohol dependence

- Medical screening to ensure suitability for treatment in a camp based programme with limited medical care facilities

- Home based detoxification to ensure short term abstinence prior to the start of the treatment camp

Patients with poor physical health, moderate to severe mental health problems and no family or social support are not included as there are limited medical care services and due to the time bound, intensive nature of the programme. These patients are referred to the TTK Hospital where they would receive free treatment for a month.

\section{Three key forces come together in phase 1}

(i) Community representatives mobilise resources to carry out the camp. Part of the building in the local school, community hall or church is made available free of cost to be converted as an addiction treatment centre for the 15-day duration of the treatment camp. The core community group actively participates by creating awareness, motivating clients to receive help and assists TTK in all logistical arrangements (food, lodging, access to medical care, etc.). The participation of the community members also provides a sense of credibility to the city-based TTK whom the rural people are not familiar with and makes it easier for the community members to trust the treatment programme.

(ii) Community members who get to know about the free addiction treatment facilities that would be available in their own village often motivate their families and friends to seek help. Their participation helps reduce stigma and ensures their support of the treatment effort. Presenting information about addiction as a disease makes it easier for drug or alcohol dependent persons and their families to seek treatment.

(iii) TTK Hospital works for about three months prior to the camp with a host organisation in the community to build awareness and carries out the screening process to select patients for the camp.

Phase 2: TTK Hospital makes available a set of trained staff (counsellors and a nurse) to conduct the programme and meets all expenses related towards food and medicine for the patients in the camp. The highly structured addiction treatment 15-day therapy programme is conducted starting with a physical exercise session in the morning and continues through the day. Evidence-based approaches such as counselling, daily group therapy sessions for the patient as well as the family are part of the programme. Lectures and group-based activities 
with participatory techniques are conducted every day. Alcoholic Anonymous members or other recovering persons in nearby communities are also invited to share about their recovery. Storytelling and art therapy sessions are also included to help patients assimilate information and develop recovery plans. Disulfiram is started from day three of the camp and patients are required to use it for one year. The TTK staff team leaves the village after the camp.

Phase 3: Follow-up is maintained by a focal person in the community who has been trained to offer support. The TTK staff team monitors the clients by coordinating closely with the focal person and is also available for support over the telephone.

Based on the success of the abovementioned TTK model in South India, the Colombo Plan Drug Advisory Programme with INL support, organised a mission to Tamil Nadu, India with Afghan village leaders, Afghan government, Afghan NGO treatment experts to adapt the camp approach to Afghanistan. The adapted model consists of three core components. These are further detailed in a treatment mapping chart.

Pre-treatment phase: The duration of this phase is approximately three months. Services include mass awareness sessions about drug abuse and motivational counseling with drug users in the selected village. Community-trained volunteers and shura (community leaders) members are mainly involved in these activities together with a few project staff.

Treatment phase: This phase includes the 21-day camp-based treatment for drug users, which is implemented in a building located in the centre of the village identified by the local community. This phase is exclusively provided by a group of trained clinical staff who conducts counseling, psycho-education and group therapy sessions. Severe cases of drug dependence were also referred to the capital of the province, Mazar-e-Sharif for residential treatment.

Post treatment (aftercare) phase: As in the TTK Model, follow-up is an essential phase in treatment. Trained staff who resides in the village monitor the clients and families. The follow-up continues for a year. Services provided in the aftercare phase are aimed to provide ongoing community-based social re-integration support to recovering clients. The aftercare and ongoing support for recovering clients will mainly be provided by the local volunteers and shura members. Sustainability of the initiative is determined by the community support particularly by the shura members, local volunteers, local related government agencies such as Ministry of Public Health, and the persons and their families with substance use disorders in the formation of self-help or support groups. 


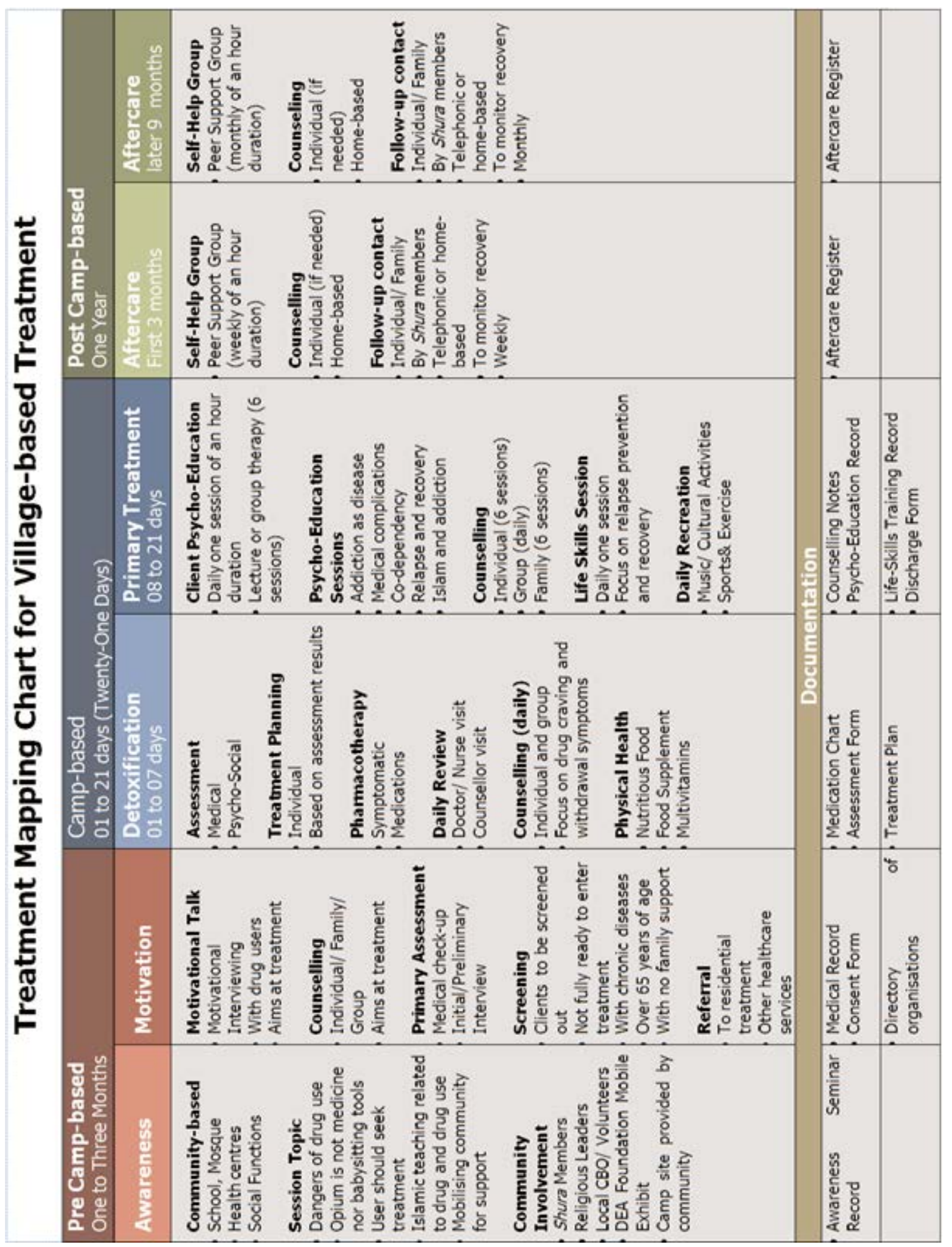




\section{Pilot project outputs}

In response to this situation, a pilot village-based treatment project was initiated in the Kaldar district of Balkh province where four villages namely Kohnar Kaldar, Ana Gilday, Qargha Eakarash and Bilek were targeted. The adapted TTK camp-based treatment approach was used in the four targeted villages from June 2012 to June 2013. Major project outcomes and highlights are presented in the below paragraphs.

A contract was awarded to an NGO partner, Shahamat Health and Rehabilitation Organization (SHRO), which operates numerous treatment centres in urban Afghanistan including a women and children centre in Mazar-e-Sharif, Balkh. The project team was mobilised in all the four villages of the Kaldar district beginning in June 2012. As per project strategy, services were provided by project staff, local shura (community group of elders) and local volunteers. The project services were divided into four categories (i.e. pre-treatment, treatment, aftercare and sustainability services).

To enable the project clinical team to work in different villages on rotation, the project activities in the four different villages started in different months after the start of the project. Activities in Ana Gilday village started in June, in Kohna Kaldar village started in August, in Qargha village started in October and in Bilek village started in November 2012. Each village was given approximately three months for the pre-treatment phase and three months for conducting three treatment camps.

In the pre-treatment phase, over 9,000 villagers were reached through awareness sessions and about 450 drug dependents received motivational counseling.

During the project period, 15 treatment camps were held where treatment services were provided to 280 clients including 100 adult men, 90 adult women and 90 children from all the four targeted villages. Of all the 15 treatment camps, five were for adult men, five for adult women and five for children.

Problems faced during the pilot project included the security situation of the urban staff working in the village. This affected the quality of services provided by the project team. Due to security reasons, female clinical staff from the Mazar-e-Sharif treatment centre could not be placed for the maximum duration in Kaldar district in order to manage the treatment camps for the female clients. The security situation also affected the monitoring schedule of the Colombo Plan treatment expert team.

Another problem faced during the treatment phase was the availability of a venue to hold the 21-day treatment camps for clients in all the four villages. The shura and local community members in each target village were expected to 
provide venues as the community contribution for conducting the 21-day treatment camp, but were unable to follow through. To address this issue, clients from all four villages were brought to Ana Gilday where the venue for treatment camp was established and supported through project resources.

The greatest underlying problem, which was not addressed effectively in this pilot project was the lack of pharmaceutical medications for analgesia that lead Afghans to self-medicate with opium and give it to their children when faced with common ailments. Many parents do not recognise the dangers of opium use or recognise that opium should not be used as medicine. In the absence of an alternative analgesic medication, villagers in recovery would be very tempted to resume opium use when faced with pain. In designing the Afghan village based model during the Indian site visits, the team emphasised that the Government of Afghanistan would need to establish some type of access to licit pharmaceutical drugs for analgesia, but these were not incorporated into the pilot project. ${ }^{8}$

In addition, many women in the villages of Kaldar district weave carpets and give opium to their children in order to make them sleep, thereby serving as a form of childcare. The team designing the village-based model discussed the option of organising a cooperative where the mothers would designate one person to care for all children and compensate them from their collective earnings. However, this arrangement was never adopted in any of the villages.

In the post treatment phase, the project staff was observed to provide more of the aftercare services compared to the shura members and community volunteers. On average, 30 clients were reached per month by the project staff compared to 6 clients per month in aftercare during the last six months of the project. Moreover, the establishment and mobilisation of self-help groups among recovering clients was another objective in the aftercare phase that indirectly suggests promising treatment outcome of the village-based model. However, only six self-help groups involving about 60 members were mobilised to conduct 21 support group meetings during the last six months of the project.

An assessment of the situation after one year revealed that aftercare support for clients who have received 21-day camp-based treatment is being provided by three sources i.e. recovery support groups, community volunteers and local shura groups. Each of these players has a different role and significance in the continuum of care for recovering clients which will continue for one year. Approximately $70 \%$ of the recovering clients completing village based treatment received some form of aftercare support.

\section{Conclusion}

The village based treatment model, based on the Indian experience and piloted 
by the Colombo Plan Drug Advisory Programme with support of INL is a pragmatic primary health care model focused on reaching the marginalised rural populations of Afghanistan. The 2012-2013 pilot project in Balkh province achieved some initial positive results, however, the pilot also faced limitations that will need to be overcome in order to make the model more effective in the future. Lack of access to medication, in particular, is a key risk factor for relapse that needs to be addressed in order to strengthen long-term treatment outcomes.

This pilot project will be expanded during the period 2013-2014 to other provinces in northern Afghanistan and strengthen its collaboration between the various government agencies such as Ministry of Public Health, Ministry of Counter Narcotics, together with the local shura, NGOs and community volunteers. The pilot project had already conducted monthly and quarterly coordination and sensitisation meetings with these stakeholders, but this collaboration will need to be intensified. With further refinement of the model, the Colombo Plan, INL and other stakeholders plan to expand village-based treatment in the coming years throughout Afghanistan. Furthermore, the model may be useful for other states with rural populations that lack treatment for substance use disorders.

\section{References}

1. Tay BH, Kim SM, Mikell S, Pannaboke N. Certification of Addiction Professionals in Asia, International Journal on the Prevention and Treatment of Substance Use Disorders, July 2013.

2. World Drug Report. UNODC. May 2013.

3. Afghanistan National Urban Drug Use Survey (ANUDUS). Bureau for International Narcotics and Law Enforcement Affairs. December 2012.

4. The Colombo Plan Drug Advisory Programme, Trip Report Regarding Village Based Treatment, June 2011. (unpublished).

5. Evans H, O’Chiese information package, Guidelines for community sobriety, University of Calagry, Nechi Institute on Alcohol and Drug Education, 1987.

6. Poshyachinda V. Indigenous treatment for drug dependence in Thailand, Impact 1984;34(1): 67- 76

7. Ranganthan S. Community approach to alcoholism treatment - an exploratory/evaluative study, doctoral thesis unpublished, 2000.

8. Morales B. Development of a Village Based Treatment Model for Afghanistan: Trip Report. Bureau for International Narcotics and Law Enforcement Affairs, U.S. Department of State, June 2011. (unpublished). 